\title{
A complex past: historical and contemporary fisheries demonstrate nonlinear dynamics and a loss of determinism
}

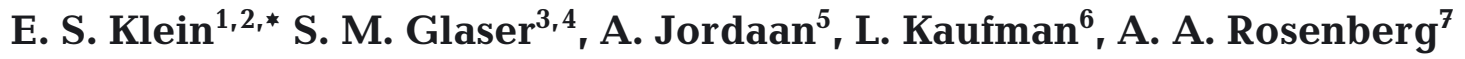 \\ ${ }^{1}$ Southwest Fisheries Science Center, 8901 La Jolla Shores Dr., La Jolla, CA 92037, USA \\ ${ }^{2}$ Farallon Institute, 101 H St., Petaluma, CA 94952, USA \\ ${ }^{3}$ Korbel School of International Studies, 2201 S. Gaylord St., University of Denver, Denver, CO 80208, USA \\ ${ }^{4}$ Secure Fisheries, One Earth Future Foundation, 525 Zang St., Broomfield, CO 80021, USA \\ ${ }^{5}$ Dept of Environmental Conservation, University of Massachusetts Amherst, 160 Holdsworth Way, Amherst, MA 01003, USA \\ ${ }^{6}$ Dept of Biology, Boston University, 5 Cummington Street, Boston, MA 02215, USA \\ ${ }^{7}$ Center for Science and Democracy, Union of Concerned Scientists, 2 Brattle Square, Cambridge, Boston, MA 02138, USA
}

\begin{abstract}
Nonlinear dynamics have been widely demonstrated in natural systems. In marine fisheries ecosystems, such dynamics have primarily been associated with exploited species, suggesting an anthropogenic stressor may explain their prevalence. However, this earlier work compared co-occurring exploited and unexploited species, as opposed to analyzing the same species before and after significant harvesting pressure. The former does not control for either differences between species or the reality of indirect and long-lasting fishing impacts. Here, nonlinear dynamics were investigated for the same species before and after significant changes in the magnitude of harvesting. We found nonlinear signatures prevalent prior to heavy industrial exploitation, and also found that these dynamics were highly deterministic. This demonstrates that nonlinearity existed in a complex marine system prior to extensive human influence and suggests such behavior may be an innate property of these populations. Results also show a reduction in deterministic dynamics post industrialization, suggesting that fishing can undermine the dynamics and resilience of marine populations and render fisheries model output less predictable for management.
\end{abstract}

KEY WORDS: Nonlinear dynamics $\cdot$ Fishing $\cdot$ Marine historical ecology $\cdot$ Bay of Fundy

\section{INTRODUCTION}

Understanding and forecasting how various drivers and stressors impact the structure and function of a given ecosystem depends on the degree to which its dynamics are predictable. Several decades ago, ecologists began to focus on the identification and exploration of nonlinear behavior (May 1974, 1976, May \& Oster 1976, Schaffer \& Kot 1985); recently, that research has centered in marine systems (e.g. Sugihara et al. 2011, Liu et al. 2012, Deyle et al. 2013, Glaser et al. 2014, Ye et al. 2015). There are both nonlinear and

${ }^{*}$ Corresponding author: emily.klein04@gmail.com linear methods for forecasting dynamics, but these methods diverge significantly with modeling structure. Linear systems behave additively: they are equal to the sum of their parts and can therefore be disassembled, each part studied independently, and overall system behavior can be understood by reassembling those parts (Finlayson 1991, Deyle \& Sugihara 2011). Nonlinear systems are non-additive and 'state dependent' (e.g. Deyle et al. 2013) and thus cannot be studied through disaggregation (Deyle \& Sugihara 2011, Glaser et al. 2011, Sugihara et al. 2012). System variables and variability cannot be in-

() The authors 2016. Open Access under Creative Commons by Attribution Licence. Use, distribution and reproduction are unrestricted. Authors and original publication must be credited. 
vestigated in isolation because they depend on the state of the system. Further, future behavior is contingent on the current state and less on defined and consistent relationships between variables, as these can change depending on conditions.

Both linear and nonlinear sources of variability are observed in nature, and research suggests that nonlinearity and chaos are omnipresent (e.g. Schaffer \& Kot 1985, Dublin et al. 1990, Pascual \& Ellner 2000). In marine systems, nonlinearity has been found in a suite of biological variables (Hsieh et al. 2005) including recruitment (Dixon et al. 1999), as well as environmental forcing (Deyle et al. 2013), species interactions and population dynamics (Benincà et al. 2008, Sugihara et al. 2011, Liu et al. 2012, 2014), stock dynamics (Glaser et al. 2011, 2014, Ye et al. 2015), density-dependence (Royer \& Fromentin 2006), and plankton communities (Scheffer et al. 2003). Moreover, integrated social-ecological systems, which describe the majority of the oceans today, exhibit a variety of possible nonlinear dynamics, including chaos (Rosser 2001). Overall, these findings suggest nonlinearity is inherent. As Sugihara (2010) argues, nature may be nonlinear.

If it is indeed nonlinear, the human enterprise may be making nature even more so. Nonlinearity appears to be especially prevalent in exploited species, signifying that anthropogenic impacts, harvesting in particular, play a key role in the emergence of nonlinear signatures (Hsieh et al. 2005, Anderson et al. 2008, Sugihara et al. 2011). Anderson et al. (2008) concluded that human-induced alteration of demographic parameters in heavily exploited species caused nonlinear signals, and therefore increasingly unstable population dynamics. Glaser et al. (2014) found that exploited fishes were more likely to exhibit nonlinear dynamics than non-target ones. They suggested this was because coupling with human systems altered natural variability. Induced nonlinearity could force systems to be less predictable when using conventional models which are often unable to detect and explore nonlinear signals and more likely to experience rapid and unexpected regime shifts and other forms of catastrophic change (Mullon et al. 2005). An increase in nonlinearity could therefore be a troubling signal of anthropogenic influence. Consequently, identifying nonlinear signals could aid in distinguishing natural variability from that induced by overfishing, perhaps offering a warning sign of system vulnerability. Yet this conflicts with previously detailed research demonstrating that nonlinear patterns are innate and not the result of human impacts (e.g. Dixon et al.
1999, Pascual \& Ellner 2000, Scheffer et al. 2003, Benincà et al. 2008, Sugihara 2010).

Given these conflicting results, how do we interpret nonlinear signals? If they are being increasingly identified in natural systems, what do they mean for our evolving knowledge of ecosystem dynamics? Moreover, predictability in a time series suggests deterministic structure in its variability and is a critical property if observations are to be used to test hypotheses, build models, or forecast future conditions. Identifying and assessing the predictability and therefore determinism of nonlinear signals is therefore key for science, as well as for management. In either case, nonlinearity can be difficult to identify and assess using traditional methods that focus on linear dynamics alone, complicating predictions and management.

Identifying nonlinearity and determining whether it is innate or a product of human influences requires novel sources of data that isolate these differences. Thus far, research identifying and exploring nonlinear behavior has relied solely on contemporary data (e.g. Anderson et al. 2008) comparing different exploited and unexploited species in the same system (e.g. Glaser et al. 2014). These approaches did not fully control for differences in life history characteristics, leaving open the possibility that variation in nonlinearity may be driven by demographic differences. In addition, species not targeted by fishing may still be indirectly affected, for example via predator-prey or competitive interactions with exploited species, but also through non-directed fisheries mortality (bycatch). A long-term view often demonstrates that human use has a legacy of ecosystem-wide effects beginning well before the scope of contemporary data sets (e.g. Pauly 1995, Jackson et al. 2001). Modern data alone may not be sufficient to clarify nonlinear behavior and its drivers, therefore missing a potentially critical aspect of variability in natural systems.

Understanding how harvesting impacts catch dynamics requires analyzing information on the same species before and after major increases in exploitation. We applied empirical dynamic modeling (EDM; Ye et al. 2015) to historical catch series for a marine system of interest during a period before industrialized fishing (1873-1920) and compared it with the same analysis on analogous contemporary data (1967-2014). This is the first time that a spectrum of dynamics, including both linear and nonlinear components, has been explored for individual species in the same ecosystem under dramatically different exploitation regimes. If nonlinearity in fish populations is principally unrelated to human activities, we 
hypothesize that significant nonlinear signatures existed before the onset of industrialization. Conversely, if nonlinearity in fish populations is mostly induced by human harvesting, we would expect a higher incidence after industrialized fishing began.

\section{MATERIALS AND METHODS}

The Bay of Fundy (BoF) is the northeastern extension of the Gulf of Maine, a semi-enclosed sea in the Northwest Atlantic, bordered by the coastlines of New Brunswick and Nova Scotia, Canada (Fig. 1). The bay experiences the highest tides in the world, as well as varied physical characteristics and circulation patterns, resulting in a productive and dynamic ecosystem (Percy 1996, Graham et al. 2002). The Bay's circulation patterns and tides cause strong mixing of water masses and significant upwelling, sus- taining abundant plankton communities and high primary productivity (Percy 1996). Resulting productivity and environmental diversity support a range of resident and migratory species at all life history stages (Lotze \& Milewski 2004).

We used a novel time series of catch statistics for the BoF to compare the same species before and after the onset of intense fishing pressure. The data are the earliest continuous time series for this ecologically and economically important marine ecosystem. In addition, while the BoF has been under human influence of some kind for thousands of years (Lotze \& Milewski 2002), these time series cover a period before a dramatic increase in fishing intensity brought about by industrialization of the Canadian fishing fleet in the early to mid-1900s. Industrialization increased fishing mortality to rates unprecedented in the history of the region. In their analysis, Anderson et al. (2008) argued that one consequence

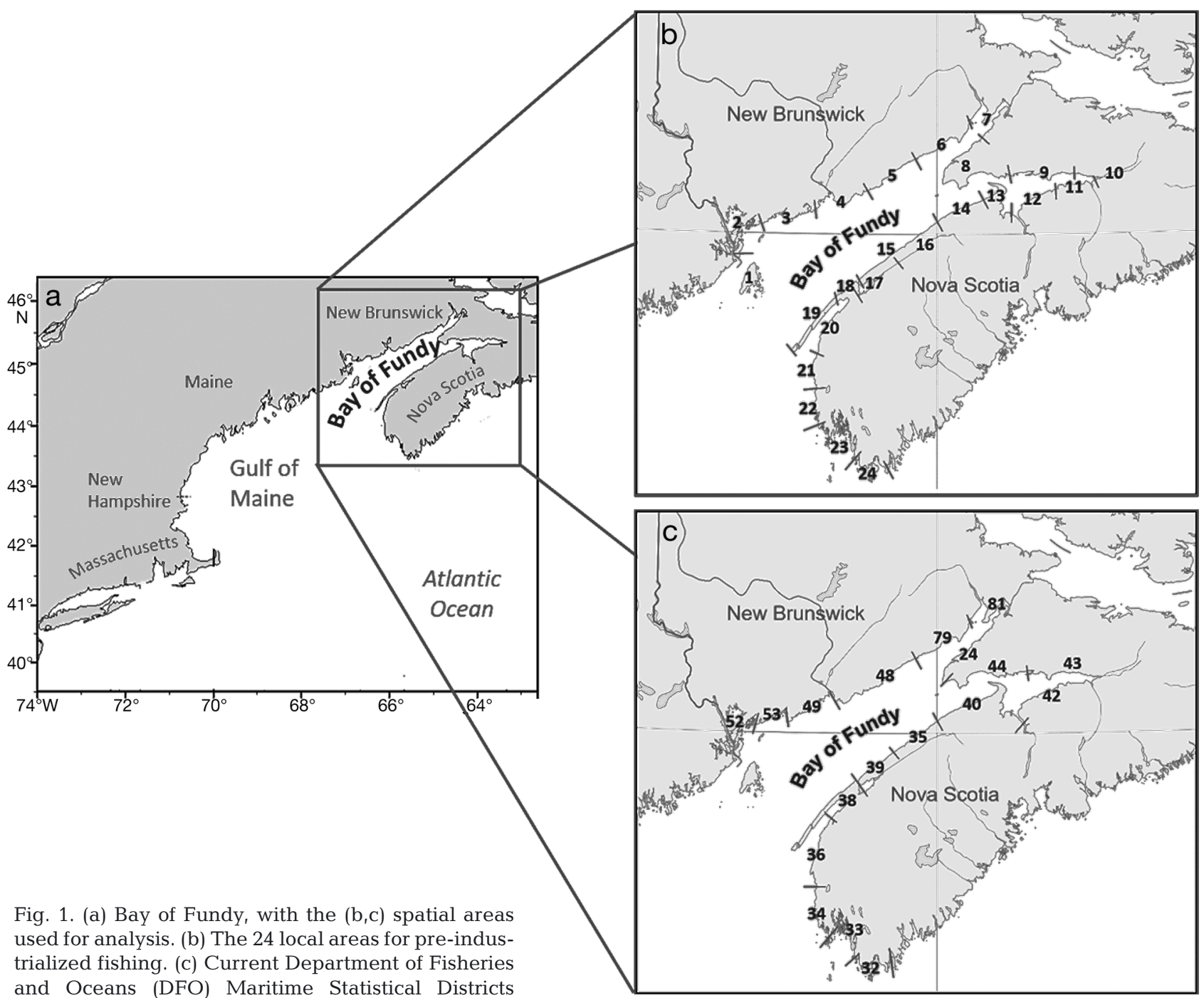


of fishing is the induction of nonlinear responses in fish populations via alterations in basic demographic parameters (namely, the intrinsic growth rate or per capital rate of population growth). In this system, we expect such consequences to have occurred after industrialization of the fishing fleet, in light of its associated and extraordinary expansion of effort.

This period of pre-industrialized fishing is covered by time series data from 1873-1920, and we compare it with similar data for the contemporary period $1967-$ 2014. These intervals provided catch time series of $47 \mathrm{yr}$, which is an appropriate run length for the analysis (Hsieh et al. 2008). For the historical period, we digitized the Canadian Department of Marine and Fisheries Reports and extracted catch statistics therein. Spatially, the data included 11 Canadian counties (Charlotte, St. John, Albert, Westmoreland, Cumberland, Colchester, Hants, Kings, Annapolis, Digby, and Yarmouth) and were reported by town, resulting in hundreds of locations. These were aggregated into 24 local areas (Fig. 1b) due to the volume of data and some variability in by-town reporting (Klein 2013) and to allow comparison with the modern data. Excluding time series with too many missing years resulted in 109 time series of appropriate length (average of $44 \mathrm{yr}$ ) and an average of 12 time series for each of 9 fish species. For the contemporary period, we analyzed catch data from 1967 to 2014. These data were at the statistical district level (21 statistical districts total), a spatial resolution comparable to that of the historical records (Fig. 1b,c). Drawing upon subsets that include only complete series resulted in 43 time series and an average of 11 time series per fish species for analysis.

Due to their ecological and economic importance, we focused on the following principal species for the historical period: Atlantic cod Gadus morhua, haddock Melanogrammus aeglefinus, pollock Pollachius virens, Atlantic salmon Salmo salar, American shad Alosa sapidissima, smelt Osmerus mordax, Atlantic herring Clupea harengus, and Atlantic mackerel Scomber scombrus, as well as one species group, gaspereau (a traditional grouping of the anadromous alewife, A. pseudoharengus, and blueback herring, A. aestivalis).

In the contemporary period, time series were available for some but not all of the species in the historical data (cod, haddock, pollock, and herring). Despite their importance historically, shad, gaspereau, and smelt were no longer commercially landed by the mid-1900s. They do not reappear in the contemporary catch records until the late 1980s, and even then only sporadically and with numerous years missing. The contemporary mackerel time series also do not return consistently until the 1980s and contained many missing years. Consequently, the time series for these 4 species were not comparably robust for further analysis. Salmon were not landed commercially at all in the contemporary statistics. This left 3 species of groundfishes plus herring as suitable for comparison of preand post-industrialized fishing dynamics.

We used catch statistics, not abundance proxies, to explore dynamics through time. As we are primarily focused on the historical period, catch data are the most consistent and reliable data available (Klein 2013). In addition, research on the historical sources for these data indicate that availability, i.e. natural fish population dynamics, drove catch statistics far more than fishing effort or market demand during that time (Klein 2013). Finally, L. Storch et al. (unpubl.) demonstrated that estimating abundance through traditional stock assessment methods can fail to conserve nonlinear signals. For these reasons, catch data were determined to be the most robust for our goals here.

Prior to analysis, time series were first-differenced $\left(\Delta X=X_{t}-X_{t-1}\right.$, where $X$ is an observation in a time series at time, $t$ ) to ensure stationarity and to reduce autocorrelation (Sugihara \& May 1990) and normalized (mean $=0, \mathrm{SD}=1$ ) to allow comparison of mean absolute error across catch series that varied by orders of magnitude. After this processing, we used EDM, introduced in Sugihara \& May (1990, as simplex projection) and Sugihara (1994, as s-map modeling) and further expanded as EDM in Ye et al. (2015), to explore both the historical and contemporary time series. EDM identifies deterministic dynamics and classifies them as linear or nonlinear by comparing the out-of-sample predictive ability of 2 models, one linear and one nonlinear. Details of the methodology are given in Sugihara \& May (1990), Sugihara (1994), Hsieh et al. (2008), and Glaser et al. (2014). Model performance was evaluated by improvement in prediction skill via the Pearson correlation coefficient, rho $(\rho)$, between model prediction and observations. We therefore consider $\rho$ to be an indicator of how predictable, and therefore how deterministic, the data were, and we confirmed precision via mean absolute error (MAE) between the observed and predicted values ( $\triangle \mathrm{MAE}$ ). We assigned a $\mathrm{p}$-value to model prediction skill using the Pearson correlation between observed and predicted values. For those time series that were significantly predictable, we analyzed their nonlinearity by the difference in predictability achieved by linear and nonlinear models. The significance of this difference was measured by a randomization test (Hsieh \& Ohman 2006) and 
Ebisuzaki tests (preserves variance and spectrum, Ebisuzaki 1997). Thus, reported p-values herein denote the statistically significant improvement in prediction of a nonlinear model over the linear model using these tests (results consistently agreed across both). Finally, ANOVAs and $t$-tests using RStudio (RStudio Team 2015) and JMP ${ }^{\circledR}$ (1989-2007, Version 12. SAS Institute, Cary, NC) software established significant differences between species and time periods. When reporting results of nonlinear analysis, only those time series with significant levels of predictability were included.

Finally, we also assessed the complexity of dynamics, represented by their dimensionality. The dimensionality of a system is the number of variables important in determining system dynamics. While dimensionality itself is unknown, it is reflected in the embedding dimensions needed to reconstruct the system behavior (Whitney 1936). Therefore, the embedding dimension provides an index of overall system complexity, and previous research has noted that changes in embedding may be further indicative of anthropogenic influence (e.g. Glaser et al. 2014).

\section{RESULTS}

Findings are summarized in Tables $1 \& 2$. Initially, we calculated baseline metrics for all species in both time periods. First, we assessed the levels of determinism in the dynamics. Either a linear or nonlinear model provided statistically significant predictions $(p<0.05)$ in almost $80 \%$ of historical time series $(84$ out of 109 time series), confirming that the data con-

Table 1. Summary of empirical dynamic modeling results for both historical and contemporary time series. Predictable values are percentage of total time series, nonlinear values are percentage of predictable time series. $\rho$ : Pearson correlation coefficient; -: not enough data

\begin{tabular}{|c|c|c|c|c|c|c|c|c|}
\hline \multirow[t]{2}{*}{ Species } & \multicolumn{4}{|c|}{ - Historical } & \multicolumn{4}{|c|}{ - Contemporary } \\
\hline & $\begin{array}{l}\text { Time series } \\
\text { (n) }\end{array}$ & $\begin{array}{c}\text { Predictable } \\
(\%)\end{array}$ & $\begin{array}{c}\text { Nonlinear } \\
(\%)\end{array}$ & $\begin{array}{c}\text { Average } \\
\rho\end{array}$ & $\begin{array}{l}\text { Time series } \\
\text { (n) }\end{array}$ & $\begin{array}{c}\text { Predictable } \\
(\%)\end{array}$ & $\begin{array}{c}\text { Nonlinear } \\
(\%)\end{array}$ & $\begin{array}{c}\text { Average } \\
\rho\end{array}$ \\
\hline \multicolumn{9}{|l|}{ Groundfish } \\
\hline Cod & 18 & 83 & 40 & 0.40 & 14 & 33 & 80 & 0.24 \\
\hline Haddock & 14 & 86 & 83 & 0.52 & 10 & 50 & 60 & 0.46 \\
\hline Pollock & 15 & 67 & 50 & 0.37 & 9 & 56 & 20 & 0.35 \\
\hline \multicolumn{9}{|c|}{ Anadromous species } \\
\hline Gaspereau & 7 & 100 & 57 & 0.46 & - & - & - & - \\
\hline Salmon & 13 & 70 & 67 & 0.36 & - & - & - & - \\
\hline Shad & 11 & 82 & 89 & 0.42 & - & - & - & - \\
\hline Smelt & 6 & 67 & 100 & 0.45 & - & - & - & - \\
\hline \multicolumn{9}{|l|}{ Pelagic } \\
\hline Mackerel & 5 & 80 & 100 & 0.47 & - & - & - & - \\
\hline Herring & 20 & 70 & 50 & 0.37 & 11 & 64 & 71 & 0.36 \\
\hline Average & & 77 & 64 & 0.42 & & 51 & 58 & 0.30 \\
\hline
\end{tabular}

Table 2. Summary of assessing the change in predictability and dynamics for comparable time series between the historical and contemporary periods in the same location. No. of comparable series: total number of time series available in both periods (number predictable in both periods). Change in predictability: number (percentage) of time series that become either predictable or unpredictable in the contemporary period. Change in dynamics: number (percentage) of time series that changed dynamic signal in the contemporary period. NP: not predictable; P: predictable; L: linear dynamics; NL: nonlinear dynamics. Embedding dimension: number (percentage) where the embedding dimension changed in the contemporary period

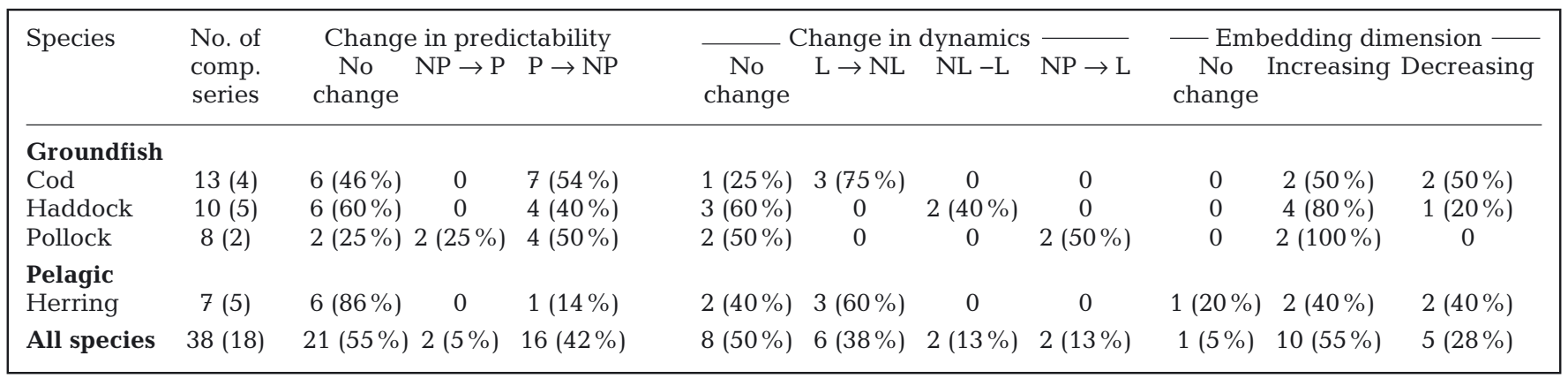


tained recoverable (deterministic and therefore predictable) temporal dynamics. Predictability was generally the same across the species we analyzed (Fig. 2a, ANOVA, p =0.38), although haddock Melanogrammus aeglefinus was marginally more predictable than pollock Pollachius virens $(\mathrm{p}=0.029)$, salmon Salmo salar ( $\mathrm{p}=0.031)$, or herring Clupea harengus (Student's $t$-test, $\mathrm{p}=0.024)$. Using a Bonferroni corrected alpha level (0.005) to control for comparisons, these differences were not considered significant. Second, nonlinear behavior was found in $70 \%$ of those time series with predictable dynamics (darker colors, Fig. 2b).

Next, to better assess changes in predictability and nonlinearity after the increase in exploitation, we compared time series for cod Gadus morhua, haddock, pollock, and herring pre- and post-industrialization of the fleet. Predictability in dynamics declined for all species in the contemporary period (Fig. $3 a)$, dropping to only $51 \%$ of collective time series (greyscale bars, Fig. 3a), compared with close to $80 \%$ during the historical period. The loss of predictability was particularly strong for cod; only $33 \%$ of the contemporary cod time series were predictable. In addi-

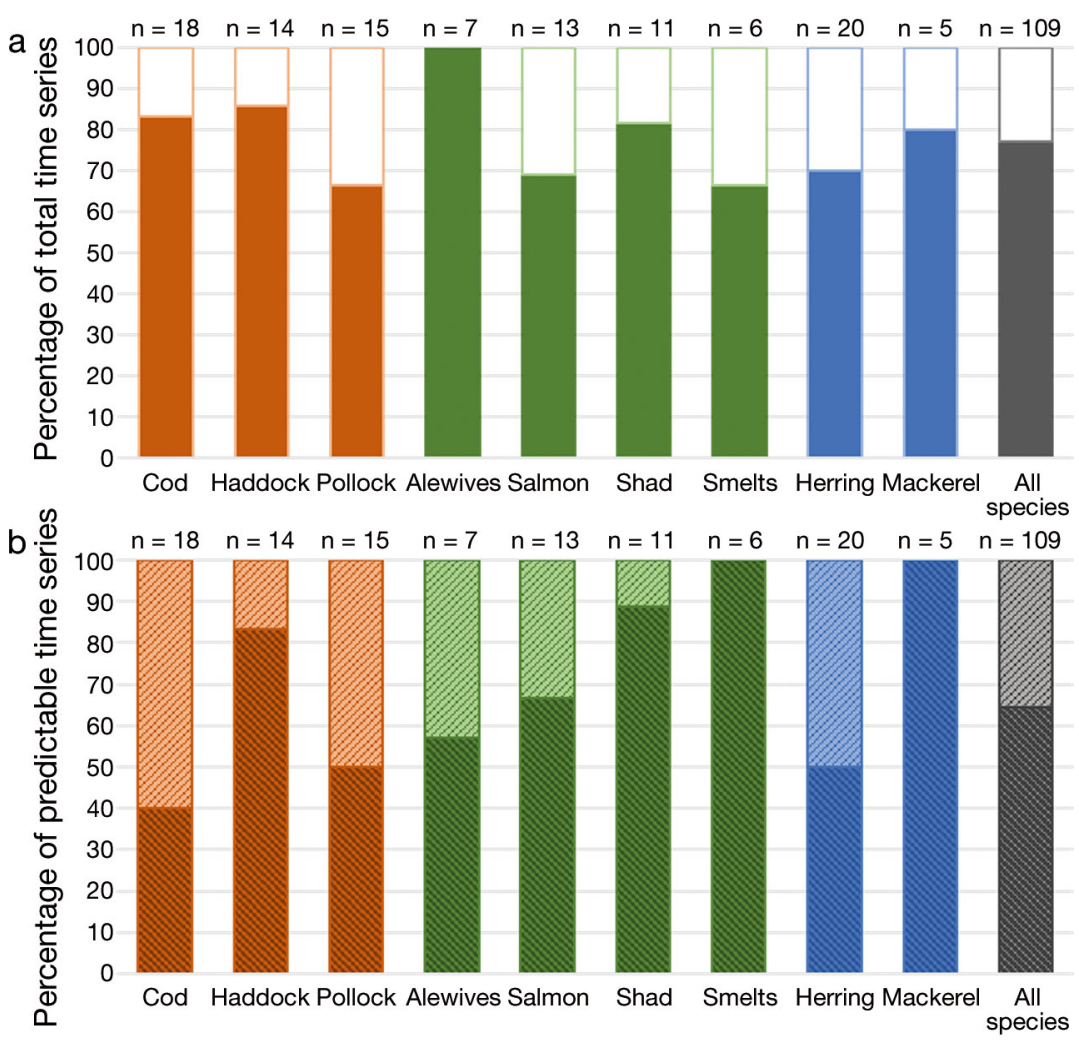

Fig. 2. Percentage of the historical time series that were (a) predictable and (b) nonlinear (darker shades) and linear (lighter shades) by species. Brown: groundfish; green: anadromous species; blue: pelagics. Gray bars on far right: average across all species tion, the average prediction skill for $\operatorname{cod}$ fell from $\rho=$ 0.40 to 0.244 .

Although there was a similar level of nonlinearity through time for those with predictable dynamics when averaged across all species (hatched gray bars, Fig 3b), dynamics had significantly higher $\rho$ values in the past (Student's $t$-test of $\rho$ values, $p=0.0057$ ). In addition, results on the prevalence of nonlinearity varied by species. Cod and herring had higher nonlinearity in the post-industrialized period, while haddock and pollock were lower (Fig. 3b). However, cod (Student's $t$-test, $\mathrm{p}=0.0172)$ and haddock $(\mathrm{p}=0.0011)$ had significantly higher predictability in the preindustrial period, while predictability for pollock $(\mathrm{p}=$ $0.236)$ and herring $(p=0.472)$ did not change.

Comparing time series at each location (Table 2), nearly half the time series were no longer predictable in the contemporary period, while only 2 time series became predictable in the contemporary catch data. There were also 25 locations with a robust time series in the past that lacked a comparable catch time series in the present (i.e. they were no longer reported as caught in the area or included too many missing observations). Cod and herring gained nonlinearity in the post-industrial period, whereas haddock and pollock gained linear dynamics There was no pattern showing whether nonlinear or linear dynamics were more likely to be lost in the contemporary period. Embedding dimension, the indicator of system complexity (Glaser et al. 2014), increased for both haddock and pollock, and in half of the time series for cod. We found no significant spatial patterns among results.

Finally, predictability was higher in time series with nonlinear dynamics than those with linear dynamics ( $t$-test, $\mathrm{p}<0.0001)$. For the historical data, predictability was higher for nonlinear than for linear series ( $\rho=$ 0.527 versus $\rho=0.384$ ). This difference was conserved (although smaller) for the contemporary data ( $\rho=0.435$ and $\rho=0.373$, respectively). Indeed, looking within each period, the difference between nonlinear and linear predictability was statistically significant in the historical period ( $t$-test, $\mathrm{p}<0.0001$ ), but not in the contemporary time series ( $t$-test, $\mathrm{p}=0.338)$. 


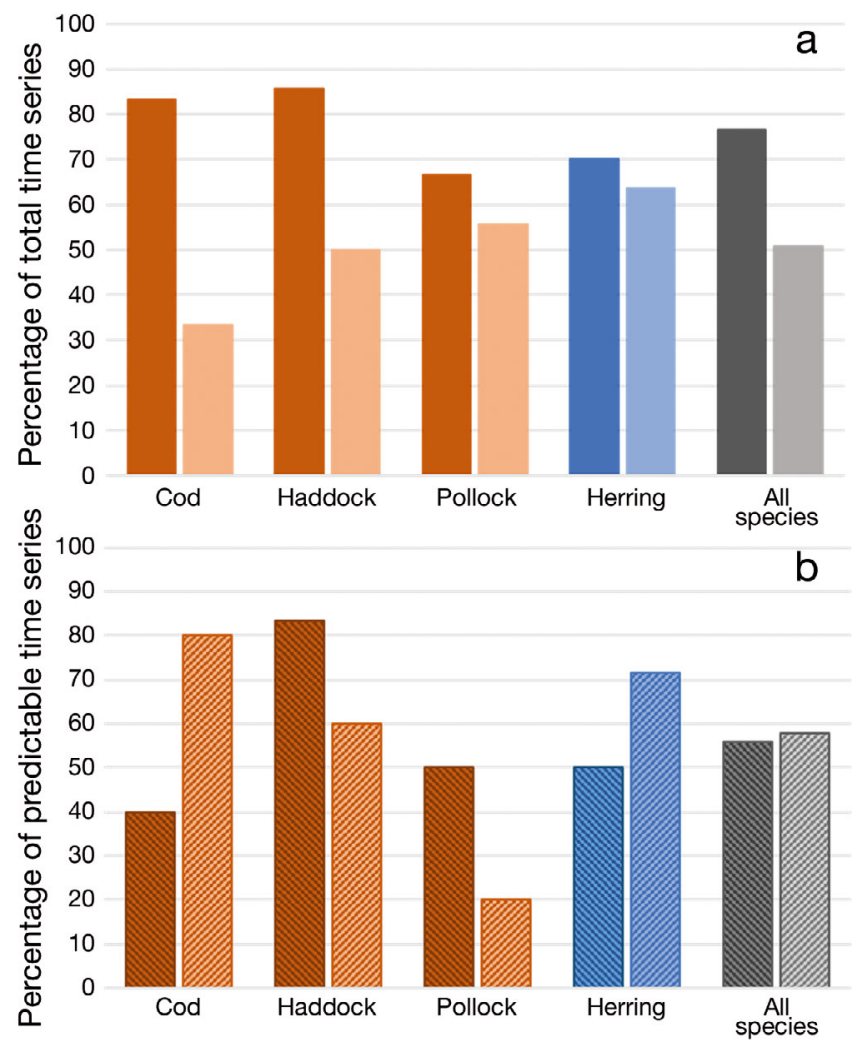

Fig. 3. Percentage of time series in the historical (left, darker bars) and the contemporary time series (right, lighter bars) that (a) are predictable (solid colors), and (b) exhibit nonlinear behavior of the predictable time series (hashed colors). Color code as in Fig. 2. Gray bars on far right: average across all species

\section{DISCUSSION}

Given earlier research, we expected lower levels of exploitation in pre-industrialized fisheries to coincide with higher levels of recoverable (i.e. predictable) dynamics and lower degrees of nonlinearity. Our results confirm the first hypothesis, while contradicting the second. The majority of the historical time series were more predictable than contemporary series, with high values for prediction skill $(\rho)$, indicating deterministic structure was more prevalent in the historical data. However, nonlinear dynamics also dominated the historical time series, and series with nonlinear signals were significantly more predictable than linear signatures. Results demonstrate that deterministic nonlinearity (as opposed to stochastic chaos, Sugihara 1994) existed in complex marine systems prior to extensive human influence and heavy exploitation. Moreover, the dynamics exhibiting nonlinear signatures were highly deterministic, further suggesting that complex behavior can be an innate property of fish populations, and accordingly, ecosystems. These findings contrast with earlier work suggesting nonlinear dynamics result from human influence.

However, whether or not nonlinearity increased or decreased with fishing intensity depended on the species analyzed. For haddock Melanogrammus aeglefinus and pollock Pollachius virens, predictability declined post industrialization of the fishing fleet, and there was a shift towards linear dynamics, in addition to an increase in embedding dimension for both species. Together, these findings indicate that, in the contemporary period, haddock and pollock may be more strongly influenced by purely stochastic, but linear, processes. In contrast, Atlantic herring Clupea harengus and cod Gadus morhua exhibited an increase in nonlinearity post-exploitation and no clear pattern in embedding dimension. Cod also saw a marked decline in predictability and exhibited the lowest percentage of time series with nonlinear dynamics in the historical period as well. Thus, the general pattern of altered nonlinearity was linked to species differences.

These findings agree somewhat with previous studies on the impact of harvesting on catch dynamics. Fishing may alter dynamics or convolute signals entirely, as argued in Glaser et al. (2014), and changes in fishing selectivity can impact the dynamic complexity of catch (Basson \& Fogarty 1997). Changes in embedding dimension (Table 2) and results for cod and herring may provide further supportive examples of these effects, yet we speculate results are not so straightforward, especially given the prevalence of nonlinearity in the historical, and less fished, time series. Moreover, the increase in nonlinearity in cod and herring may result from differing mechanisms. Cod and herring have been under significant human influence for centuries, but herring, unlike cod, are not considered overfished today. If herring catch dynamics are nonlinear, as were the majority of the historical time series across species, conservation of these signals may be another indicator of stock health. This would make sense if herring are more resilient to fishing pressure, and if they recover more quickly (Hutchings 2000). In contrast, the declines in determinism and increases in nonlinearity in the remaining time series for cod may indicate consequences of fishing found in Anderson et al. (2008). Cod remain overfished today, with biomass levels currently at all-time lows (NEFSC 2014), and they have the longest history of human exploitation among the species here; they were already heavily fished by the time the catch statistics we used 
were collected (Leavenworth 2008, Alexander et al. 2009). Further, reports of fishing impacts on cod demographic parameters, i.e. those important in the Anderson et al. (2008) study, date back to the 19th century (Klein 2013).

It is important to recognize that our analysis did not assess the importance of other impacts, either anthropogenic or environmental, and we recognize there are limits to the interpretation of catch time series as reflecting properties of the biological system. Further work is required to clarify the drivers that contribute to nonlinear dynamics, how these may change in response to both environmental and anthropogenic stressors, and most importantly, the mechanisms that drive the dynamics observed empirically. Therefore, mechanistic modeling and analyses are needed to fully explore what aspects of fishing, fishermen behavior, and environmental change may be at play. Increased fishing effort is certainly the most significant factor during the period analyzed here, and we do note changes in embedding dimension, which may be an indicator of coupling with fisheries systems (Basson \& Fogarty 1997, Glaser et al. 2014). However, recent warming and species biology have been postulated to drive dynamics in the region at the population level for some species (e.g. for cod: Fogarty et al. 2008, Pershing et al. 2015), and they remain likely additional critical influences. The historical records are constrained for further exploration of these influences via the analyses here, and additional approaches and data sources will be needed.

Overall, however, our results suggest that associating nonlinear signals with anthropogenic influence alone may be simplistic. The historical catch was overwhelmingly nonlinear in nature and more deterministic. Indeed, the loss of deterministic structure with higher exploitation rates is a significant finding of this work. Almost $80 \%$ of the historical data were predictable, but both the prevalence and strength ( $\rho$ values) of predictability declined post-industrialization, especially for haddock and precipitously for cod. This change is irrespective of differences in life history between the species. Predictability in a time series suggests deterministic structure in its variability and is a critical property if observations are to be used to test hypotheses, build models, or forecast future conditions. Here, a possible explanation for this change is that anthropogenic pressure increased the susceptibility of populations to stochastic forcing, resulting in indeterminate variability dominating previously deterministic dynamics.

Regardless of the mechanisms, these changes in dynamics have the potential to undermine resilience in the exploited stock, with implications for fisheries management and the economics of fishing. Stock assessments suffer when population trends become less predictable over time, reducing stakeholders' faith in the ability of agencies to manage the resource effectively. Perceived risk may also inhibit capital investment in fisheries innovation. Further, the loss of a number of key historical fisheries in the contemporary time series was a critical change in the system, suggesting that ecosystem functioning has likely been altered through reduced biomass of a number of populations, especially anadromous fish (Klein 2013).

The loss of deterministic structure in the contemporary system has further sobering implications, indicating exploitation can disrupt marine populations in ways beyond lowering stock abundance. We often view fishermen as predators, acting as a source of mortality for individual species in the system. Consequently, fishing mortality is incorporated into fishery models as a single, additive term (fishing mortality, $F)$. Historically and in some systems this may have been appropriate, but our findings suggest it is not always the case. Anthropogenic disruption can act on the fundamental dynamics of the system, transcending impacts of other predators (see also Hsieh et al. 2006). If this is the case, fishing can no longer been seen as affecting the ecosystem simply via a single mortality rate. Rather, it is a dynamical factor with the potential to change the entire equation. If this is indeed a generality in fisheries, it will be critical to account for in assessing ecosystems dynamics and fisheries management, particularly in a changing climate.

There is increasing evidence for nonlinear dynamics in contemporary ocean environments, yet this work is the first to evaluate such dynamics for marine species across eras of differing fishing pressure to more fully comprehend the impact of exploitation. Previous work connecting exploitation and nonlinear signals compared co-occurring exploited and unexploited species, but in so doing could not control for differences among the species or indirect and longlasting effects of exploitation. The data analyzed here provide a more rigorous test by investigating species prior to intense exploitation and comparing across very different levels of fishing pressure. The dominance of nonlinearity in time series from the less impacted historical system demonstrates that these signals occur in systems less impacted by harvesting, especially given evidence that catch more closely reflected population dynamics in the past (Klein 2013). This highlights the importance of nonlinear 
signals in fish populations and for fishery management as it is practiced today, even if stocks are considered healthy.

Identification of nonlinear signals in ecological and environmental data across ecosystems will be critical for furthering this research. Yet, identifying the driving mechanisms will be difficult if we limit analysis to contemporary data. Historical records can add invaluable information to the exploration of coupled human and natural systems, and particularly to our awareness of nonlinear dynamics. Moreover, given the current state of the world's oceans, historical records may be the best - and perhaps only - source for information about populations at lower levels of anthropogenic pressure than those of today. Scientific study of marine systems through time, i.e. marine historical ecology and environmental history, is a robust and growing area of research, and long-term data are increasingly available and applied (e.g. Thurstan et al. 2015, Engelhard et al. 2016). This is a rich area for future efforts.

Acknowledgements. E.S.K. is deeply indebted to the unfailing support and thoughtful comments provided by W. B. Leavenworth and K. E. Alexander, and all authors thank H. Ye, E. Deyle, and G. Sugihara for their considerable help as well. The work also would not be possible without assistance from the Canadian Department of Fisheries and Oceans (DFO), whose scientists and librarians allowed access to their libraries and archives, with particular thanks to J. Fife and R. L. Stephenson. In addition, D. J. Knox and M. Powers were essential for providing contemporary statistics on the Bay of Fundy. All authors thank M. Fogarty for his helpful and insightful comments, as well as 2 anonymous reviewers whose feedback improved the manuscript. The work was supported by the NOAA Nancy Foster Scholarship and by the Lenfest Ocean Program.

\section{LITERATURE CITED}

Alexander KE, Leavenworth WB, Cournane J, Cooper AB and others (2009) Gulf of Maine cod in 1861: historical analysis of fishery logbooks, with ecosystem implications. Fish Fish 10:428-449

> Anderson CNK, Hsieh CH, Sandin SA, Hewitt R and others (2008) Why fishing magnifies fluctuations in fish abundance. Nature 452:835-839

Basson M, Fogarty MJ (1997) Harvesting in discrete-time predator-prey systems. Math Biosci 141:41-74

> Benincà E, Huisman J, Heerkloss R, Johnk KD and others (2008) Chaos in a long-term experiment with a plankton community. Nature 451:822-825

- Deyle ER, Sugihara G (2011) Generalized theorems for nonlinear state space reconstruction. PLOS ONE 6:e18295

> Deyle ER, Fogarty M, Hsieh CH, Kaufman L and others (2013) Predicting climate effects on Pacific sardine. Proc Natl Acad Sci USA 110:6430-6435

> Dixon PA, Milicich MJ, Sugihara G (1999) Episodic fluctuations in larval supply. Science 283:1528-1530
Dublin HT, Sinclair ARE, McGlade J (1990) Elephants and fire as causes of multiple stable states in the Serengeti Mara Woodlands. J Anim Ecol 59:1147-1164

$>$ Ebisuzaki W (1997) A method to estimate the statistical significance of a correlation when the data are serially correlated. J Clim 10:2147-2153

> Engelhard GH, Thurstan RH, MacKenzie BR, Alleway HK and others (2016) ICES meets marine historical ecology: placing the history of fish and fisheries in current policy context. ICES J Mar Sci 73:1386-1403

Finlayson C (1991) Notes on chaos in fisheries management by Estellie Smith. MAST 3:91-97

Fogarty M, Incze L, Hayhoe K, Mountain D, Manning J (2008) Potential climate change impacts on Atlantic cod (Gadus morhua) off the northeastern USA. Mitig Adapt Strategies Glob Change 13:453-466

Glaser SM, Ye H, Maunder M, MacCall A, Fogarty M, Sugihara G (2011) Detecting and forecasting complex nonlinear dynamics in spatially structured catch-per-unit-effort time series for North Pacific albacore (Thunnus alalunga). Can J Fish Aquat Sci 68:400-412

Glaser SM, Fogarty M, Liu H, Altman I and others (2014) Complex dynamics may limit prediction in marine fisheries. Fish Fish 15:616-633

Graham J, Engle S, Recchia M (2002) Local knowledge and local stocks: an atlas of groundfish spawning in the Bay of Fundy. Center for Community-Based Management, St. Francis Xacier University, Antigonish

Hsieh CH, Ohman MD (2006) Biological responses to environmental forcing: the linear tracking window hypothesis. Ecology 87:1932-1938

Hsieh CH, Glaser SM, Lucas AJ, Sugihara G (2005) Distinguishing random environmental fluctuations from ecological catastrophes for the North Pacific Ocean. Nature 435:336-340

- Hsieh CH, Reiss CS, Hunter JR, Beddington JR, May RM, Sugihara G (2006) Fishing elevates variability in the abundance of exploited species. Nature 443:859-862

Hsieh CH, Anderson C, Sugihara G (2008) Extending nonlinear analysis to short ecological time series. Am Nat 171:71-80

Hutchings JA (2000) Collapse and recovery of marine fishes. Nature 406:882-885

Jackson JBC, Kirby MX, Berger WH, Bjorndal KA and others (2001) Historical overfishing and the recent collapse of coastal ecosystems. Science 293:629-637

Klein ES (2013) Change in nonlinear dynamics and spatial structure of coastal socio-ecological systems: Bay of Fundy as case study. PhD Dissertation, University of New Hampshire, Durham, NH

Leavenworth WB (2008) The changing landscape of maritime resources in seventeenth-century New England. Int J Marit Hist 20:33-62

Liu H, Fogarty MJ, Glaser SM, Altman I and others (2012) Nonlinear dynamic features and co-predictability of the Georges Bank fish community. Mar Ecol Prog Ser 464: 195-207

> Liu H, Fogarty MJ, Hare JA, Hsieh CH and others (2014) Modeling dynamic interactions and coherence between marine zooplankton and fishes linked to environmental variability. J Mar Syst 131:120-129

Lotze HK, Milewski I (2002) Two hundred years of ecosystem and food web changes in the Quoddy Region, outer Bay of Fundy. Conservation Council of New Brunswick, Fredericton 
Lotze HK, Milewski I (2004) Two centuries of multiple human impacts and successive changes in a North Atlantic food web. Ecol Appl 14:1428-1447

May RM (1974) Biological populations with nonoverlapping generations: stable points, stable cycles, and chaos. Science 186:645-647

May RM (1976) Simple mathematical-models with very complicated dynamics. Nature 261:459-467

May RM, Oster GF (1976) Bifurcations and dynamic complexity in simple ecological models. Am Nat 110:573-599

Mullon C, Freon P, Cury P (2005) The dynamics of collapse in world fisheries. Fish Fish 6:111-120

NEFSC (2014) Gulf of Maine Atlantic cod, 2014 assessment update report. National Oceanic and Atmospheric Administration, Woods Hole, MA

Pascual M, Ellner SP (2000) Linking ecological patterns to environmental forcing via nonlinear time series models. Ecology 81:2767-2780

Pauly D (1995) Anecdotes and the shifting base-line syndrome of fisheries. Trends Ecol Evol 10:430

Percy JA (1996) Tides of change: natural processes in the Bay of Fundy. Bay of Fundy Ecosystem Project: Fundy Issues. Clean Annapolis Rivers Project. Annapolis Royal, www.bofep.org/natural.htm

Pershing AJ, Alexander MA, Hernandez CM, Kerr LA and others (2015) Slow adaptation in the face of rapid warming leads to collapse of the Gulf of Maine cod fishery. Science 350:809-812

Rosser JB (2001) Complex ecologic-economic dynamics and environmental policy. Ecol Econ 37:23-37

Royer F, Fromentin JM (2006) Recurrent and densitydependent patterns in long-term fluctuations of Atlan-

Editorial responsibility: Jake Rice,

Ottawa, Ontario, Canada tic bluefin tuna trap catches. Mar Ecol Prog Ser 319: $237-249$

RStudio Team (2015) RStudio: integrated development for R. RStudio, Boston, MA

Schaffer WM, Kot M (1985) Do strange attractors govern ecological-systems? Bioscience 35:342-350

Scheffer M, Rinaldi S, Huisman J, Weissing FJ (2003) Why plankton communities have no equilibrium: solutions to the paradox. Hydrobiologia 491:9-18

Sugihara G (1994) Nonlinear forecasting for the classification of natural time-series. Philos Trans R Soc Lond A 348:477-495

Sugihara G (2010) Nature is nonlinear. Kyoto Journal 75:56

Sugihara G, May RM (1990) Nonlinear forecasting as a way of distinguishing chaos from measurement error in timeseries. Nature 344:734-741

Sugihara G, Beddington J, Hsieh Ch, Deyle E and others (2011) Are exploited fish populations stable? Proc Natl Acad Sci USA 108:E1224-E1225

Sugihara G, May R, Ye H, Hsieh CH, Deyle E, Fogarty M, Munch S (2012) Detecting causality in complex ecosystems. Science 338:496-500

> Thurstan RH, McClenachan L, Crowder LB, Drew JA and others (2015) Filling historical data gaps to foster solutions in marine conservation. Ocean Coast Manag 115: $31-40$

Whitney H (1936) Differentiable manifolds. Ann Math, 2nd Series 37:645-680

Ye H, Beamish RJ, Glaser SM, Grant SCH and others (2015) Equation-free mechanistic ecosystem forecasting using empirical dynamic modeling. Proc Natl Acad Sci USA 112:E1569-E1576

Submitted: March 11, 2016; Accepted: August 29, 2016

Proofs received from author(s): September 22, 2016 